\title{
OUR EXPERIENCE WITH TOPOTECAN AS SECOND- LINE TREATMENT OF PATIENTS WITH RELAPSED SMALL CELL LUNG CANCER
}

\author{
Deyan Davidov, \\ Department of Chemotherapy, Oncological Center, \\ Medical University, Pleven, Bulgaria
}

\section{RESUME:}

Objectives: Single agent intravenous Topotecan is an effective treatment for small cell lung cancer /SCLC/ after failure of first- line chemotherapy. The aim of this study was to evaluate the efficacy and toxicity of intravenous Topotecan in recurrent SCCC. Methods: In the period 20082009 seventeen

consecutive patients with relapsed SCLC entered the study. The treatment schedule consists of Topotecan $1,5 \mathrm{mg} /$ $\mathrm{m} 2$ i.v. for five consecutive days, with repetition every 21 days. Results: Overall response rate was 23,5\%. Median survival was 6,4 months. Nausea, vomiting and neutropenia were most common side effects. Conclusion: Intravenous Topotecan is effective as second- line therapy for patients with relapsed SCCC with good tolerability.

Key words: Relapsed small cell lung cancer, Secondline treatment, Intravenous Topotecan, Survival

\section{INTRODUCTION}

Lung cancer is the most common cancer worldwide with an estimated 174, 470 new cases diagnosed and 162,460 deaths in the United States in 2006 year /1/. Small cell lung cancer /SCLC/ represents about $20 \%-25 \%$ of all lung cancers, making SCLC the seventh most frequent case of cancer death $/ 2 /$. Patients with SCLC frequently present with widely metastatic disease. Only $30 \%-40 \%$ of patients present with limited- stage disease $/ \mathrm{LD} /$. LD- SCLC is defined as disease confirmed in only one hemithorax, with or without regional lymph nodes, with or without ipsilateral supraclavicular lymph nodes involvement, and without ipsilateral pleural effusions. Extensive disease /ED/ is defined as disease that have spread beyond these boundaries. This distinction is important in regard to treatment and prognosis /3/. SCLC is considered to be among the most chemosensitive solid tumors $/ 4 /$. With combination chemotherapy, such as cis- Platinum/ Etoposide or Cyclophosphamide/ Doxorubicin/ Etoposide, objective response rate of $20 \%-90 \%$ are observed, with a median survival of more than 10 months. However, the majority of patients will experience tumor recurrence after successful therapy $/ 5 /$. Prognosis for patients with relapsed SCCL is poor; expected survival in untreated patients is 2 to 3 months. Response to second- line therapy most likely depends on response to first- line treatment and length of the treatment- free interval. Patients developing disease progression within 3 months after first- line therapy are classified as refractory. Patients with disease progression $>$ 3 months after the last treatment of first- line therapy, which has induced an objective response, are classified as sensitive $/ 6 /$.

Topotecan is a drug originating from a family of chemoterapeutic agents that inhibit the DNA topoisomerase I enzyme. The DNA topoisomerase I enzyme is responsible for relaxing a supercoiled DNA helix during DNA synthesis. Topoisomerase I inhibitors inhibit the religation step of the enzymatic reaction by stabilizing the DNA enzyme complex. It then causes accumulations of persistent single strand DNA breaks. After the inhibitions of enzyme, Topotecan cause cell death $/ 7 /$. Topotecan was reported to be effective as second- line treatment for relapsed SCLC /8/. In a randomized phase II study of single agent intravenous Topotecan at dose $1,5 \mathrm{mg} / \mathrm{m} 2$ days $1-5$ have shown response rates of $14 \%$ to $38 \%$ among sensitive patients. Among refractory patients response rate were $2 \%$ to $6 \%$. Median survival time was 26 to 28 weeks for sensitive patients compared with 16 to 20 weeks for refractory patients. Response rate for all sensitive patients was $18 \%$ and a median survival time of 30 weeks $/ 9 /$.

The aim of this study was to evaluate the efficacy and safety of intravenous Topotecan in patients with relapsed SCLC.

\section{PATIENTS AND METHODS}

Seventeen patients with histologically or cytologically proven relapsed SCLC cancer, treated in the period 2008- 2009 in Medical University- Pleven, Oncological center, Department of Chemotherapy, who met the following criteria, entered the study. The patients had been treated with one regimen of chemo/ radiotherapy or one regimen of 
chemotherapy; the tumor responded to first- line chemotherapy but recurred later; the last chemotherapy was finished at least 8 weeks commencing study treatment.

To be eligible for inclusion in the study participants needed to be between 18 and 75 years of age, have measurable metastatic disease, life expectancy of minimum three months, World Health Organisation /WHO/ performance status / PS/ 0 to 2, adequate bone marrow function /absolute granulocyte count $>1,5 \times 10^{9} / \mathrm{L}$, platelet count $>140 \times 10^{9} / \mathrm{L} /$ as well as normal renal $/$ serum creatinine level $<1,5 \mathrm{mmol} / \mathrm{L} /$ and hepatic function/serum bilirubin level $<21 \mathrm{mmol} / \mathrm{L} /$, absence of active infections, no overt cardiac disease, no active concomitant malignancy. Patients with severe drug hypersensitivity, interstitial pneumonia, pulmonary fibrosis, symptomatic brain metastases, massive pleural effusion, ascites or other severe complications were excluded from the study. Patients who were pregnant, nursing, or expressed a desire to become pregnant were also ineligible. All patients underwent a routine staging evaluation that consisted of standard radiological studies. Measurable disease was defined as the tumor demonstrated by conventional chest roentgenography or computed tomography of the whole body.

One course treatment consisted of a 5- day repeat dosing of Topotecan $1,5 \mathrm{mg} / \mathrm{m} 2 /$ day administered intravenous by drip infusion over $60 \mathrm{~min}$. period, with repetition every 21 days until progression.

Patients were evaluated for tumor response before treatment and after third and sixth course of chemotherapy. Tumor response was evaluated according to WHO response criteria /10/. Response was defined as complete response / $\mathrm{CR} /$, partial response $/ \mathrm{PR} /$, no change $/ \mathrm{NC} /$, or progressive disease /PD/. A CR was defined by the disappearance of all known disease, confirmed by two observations not less than 4 weeks apart. PR was defined as a decrease in tumor size of $50 \%$ or more /either measured or estimated in the case of measurable or assessable disease/. In addition, there could be no appearance of any new lesions or progression of any known lesion(s). Objective tumor response included both confirmed CR and PR. Safety was assessed using the WHO toxicity criteria $/ 11 /$.

The duration of response was calculated from the day of the start of treatment to disease progression; overall survival was measured from study entry to death. The time to disease progression was calculated from study entry until the day of the first evidence of disease progression. The actuarial survival was estimated by the method of Kaplan and Meyer $/ 12 /$.

\section{RESULTS}

A total of seventeen patients with relapsed SCLC were enrolled in the study over a 18 - months period. Data were collected for an additional 12 months after accrual ended, with data on survival collected through February
2010. All patients regardless of their length of treatment were included in analysis. Tumor response was evaluated for all patients who received at least one dose of Topotecan. Some patient's characteristics are listed in Table 1. Twelve patients were male and five females. Four patients had a WHO PS0 , nine had a PS- 1 and four had a PS of 2 . The majority of patients $/ 64,7 \%$ / had distant metastases. In addition, eleven patients were with ED and six with LD. The sites for evaluation were primary tumor, lymph nodes and metastatic lesions in liver, lung and others. As previous chemotherapy, combination therapy with a Platinum preparation and Etoposide was used in $70,6 \%$ patients. The overall response rate to primary therapy was $76,5 \%$. In total $35,3 \%$ was refractory, whereas $64,7 \%$ of patients were sensitive to prior therapy. The median time to progression after first- line therapy was 187 days. The safety was assessed in all 17 patients. Median duration of treatment was 5,5 months. The median follow- up period was 8,5 months.

\section{Efficacy}

The resulting antitumor effects are presented in Table 2. The four partial remissions were obtained. The overall response rate /ORR/ was $23,5 \% / 4$ of $17 /$. No change was observed in $6 / 35,3 \%$ / and progressive disease in $7 / 41,2 \% /$ showing that chemotherapy had induced a significant efficacy. No difference in response rate was seen between patients with and without platinum- containing pretreatment. However, patients who had been refractory to primary chemotherapy achieved a lower response rate and a higher rate of disease stabilization to Topotecan therapy. Among all responding patients median time to response was 6,9 weeks. Median duration of response was 11,7 weeks and was not significantly different among the subgroups. Median survival time was 24,2 weeks. After one year two patients were alive according to 1 -year survival rate of $11,7 \%$.

\section{Safety}

Table 3 and 4 presents the incidence of hematological and nonhematological adverse drug reactions grade 3- 4 that occurred in entire group. Toxicity grade III- IV was observed in $17,6 \%$ of the patients and never was fatal. The highest incidence was nausea, vomiting and neutropenia. Most of these symptoms were rated as grade 2 or 1 . Chemotherapy delays of $>14$ days due to hematological toxicity- leukopenia, anemia or thrombocitopenia, was observed in two patients. Treatment- related deaths were not observed. Non- hematological toxicity of grade 3- 4 included mainly vomiting, nausea, fever and pain.

\section{DISCUSSION}

Despite the high chemosensitivity of SCLC, the majority of patients have a relapse after induction therapy. The prognosis of patients with recurrent disease remains 
poor. The goals of chemotherapy in this patient's population were to obtain maximum control of disease symptoms, prevent serious complications and increase survival without diminishing quality of life/13/. In the current study we evaluated efficacy and safety of intravenous Topotecan as second- line chemotherapy for patients with relapsed SCLC. Topotecan- containing regimes have been the most commonly used chemotherapy protocols for relapsed SCLC. The overall response rate$23,5 \%$, obtained in this study is promising. These results are comparable with previously published reports using intravenous Topotecan in the standard dosage $/ 9,14 /$. In these studies median survival was $23-26$ weeks with time

Table 1. Patient characteristics

\begin{tabular}{|c|c|}
\hline Patient characteristics & $\begin{array}{l}\text { Number } \\
\text { of patients }\end{array}$ \\
\hline Median age (years) & $43-76$ \\
\hline Sex & \\
\hline Males & $12(70,6 \%)$ \\
\hline Females & $5(29,4 \%)$ \\
\hline WHO Performance status & \\
\hline 0 & $4(23,5 \%)$ \\
\hline 1 & $9(54,0 \%)$ \\
\hline 2 & $4(23,5 \%)$ \\
\hline Extend of disease & \\
\hline Limited disease & $6(35,3 \%)$ \\
\hline Extensive disease & $11(64,7 \%)$ \\
\hline Time to relapse to first-line therapy & \\
\hline$<3$ months refractory & $6(35,3 \%)$ \\
\hline$>3$ months sensitive & $11(64,7 \%)$ \\
\hline First line chemotherapy & \\
\hline Plainum- based & $12(70,6 \%)$ \\
\hline Nonplatinum- based & $5(29,4 \%)$ \\
\hline Number of measured lesions & \\
\hline 1 & $8(47,0 \%)$ \\
\hline 2 & $5(29,4 \%)$ \\
\hline 3 & $4(23,6 \%)$ \\
\hline Site of lesion evaluated & \\
\hline Primary tumor & $14(82,3 \%)$ \\
\hline Metastatic tumor & $11(64,7 \%)$ \\
\hline Lymph node & $9(52,9 \%)$ \\
\hline Liver & $7(41,2 \%)$ \\
\hline Lung & $3(17,6 \%)$ \\
\hline Others & $5(29,4 \%)$ \\
\hline $\begin{array}{l}\text { Time to progression after first- line } \\
\text { chemotherapy }\end{array}$ & 187 days \\
\hline
\end{tabular}

to progression of 6- 8 weeks. As expected, the response rate was higher in sensitive patients- $17,6 \%$ than in refractory patients. Median duration of response was 11,7 weeks for all patients. The median survival duration was 6,4 months.

In the majority of patients the chemotherapy regimen was well tolerated. Both hematological and nonhematological toxicity was mild to moderate and chemotherapy was not stopped because of toxicity. Grade 3 or 4 toxicity were rare and never was fatal.

In conclusion, the results of the present study indicate that Topotecan treatment for patients with relapsed SCLC appears promising with of survival rate of 6,4 months and low toxicity.

Table 2. Objective responses

\begin{tabular}{|l|c|c|c|c|c|}
\hline $\begin{array}{l}\text { Patients/ } \\
\text { Response }\end{array}$ & CR & PR & NC & PD & ORR\% \\
\hline 17 & - & 4 & 6 & 7 & $23,5 \%$ \\
\hline
\end{tabular}

$\mathrm{ORR}=\mathrm{CR}+\mathrm{PR}$

$\mathrm{CR}$, complete response; PR, partial response; NC, no change; $\mathrm{PD}$, progressive disease; ORR, overall objective response rates;

Table 3. Adverse drug reactions by symptoms: grade 3 and 4 non-hematological toxicity

\begin{tabular}{|l|c|}
\hline Adverse drug reactions & Number of patients \\
\hline Nausea & $2(11,7 \%)$ \\
Vomiting & $2(11,7 \%)$ \\
Fever & $1(5,9 \%)$ \\
Pain & $1(5,9 \%)$ \\
\hline
\end{tabular}

Table 4. Adverse drug reactions by symptoms: grade 3 and 4 haematological toxicities

\begin{tabular}{|l|c|}
\hline Adverse drug reactions & Number of patients \\
\hline Leucopenia & $3(17,6 \%)$ \\
Thrombocytopenia & $2(11,7 \%)$ \\
Anaemia & $2(11,7 \%)$ \\
\hline
\end{tabular}




\section{REFERENCES:}

1. Jemal A, Siegel R, Ward E et al, Cancer Statistics, 2006. CA Cancer J Clin 2006; 56: 106- 130

2. Feld R, Ginsberg RJ, Rayne DG et al, Lung. In: Abeloff MD, Armitage JO, Lichter AS et al., eds. Clinical Oncology, New York: Churchill Livingstone, Inc., 1995: 1118- 1141

3. Rosti G, Bevilacqua G, Bidoli P et al, Small cell lung cancer, Ann Oncol, 2006; 17: /suppl 2/, ii5- ii 10

4. Carney DN, Shepherd FA, Treatment of SCLC: chemotherapy. In: Hansen NN, ed. Textbook of lung cancer. London, Martin Dunitz Ltd, 2000; 261272

5. Murren J, Clatstein E, Pass $\mathrm{H}$ et al, Small cell lung cancer. In: De Vita VT, Hellman S, Rosenberg S, eds. Cancer: Principles and practice in oncology. Philadelphia, Lippincott, Williams and
Wilkins, 2001, 983- 1018

6. Giaccone G, Splinter T, Debruyne C et al, Randomized study of paclitaxelcisplatin versus cisplatin- teniposide in patients with advanced non- small- cell lung cancer, J Clin Oncol, 1998; 16: 2133- 2141

7. Takimoto C, Abruck S, Campothecins, In: Chabner B, Long D, eds. Cancer chemotherapy and Biotherapy, Second edition, Philadelphia, LippincottRaven, 1996; 463- 484

8. Ardizoni A, Hansen $\mathrm{H}$, Dombernowsky $\mathrm{P}$ et al, Topotecan, a new active drug in second- line treatment of small cell lung cancer: a phase II study in patients with refractory and sensitive disease, J Clin Oncol, 1997; 15: 2090- 2096

9. Von Pavel J, Schiller J, Shepherd F et al, Topotecan versus cyclophosphamide, doxorubicin, and vincristin for the treatment of recurrent small cell lung cancer, J Clin Oncol 1999; 17: 658- 667

10. Miller AB, Hoogstraten B, Staquet $M$ et al, Reporting results of cancer treatment. Cancer 1981; 47; 207-214

11. Brimdage MD, Pater JL, Zee B, Assessing the reliability of two toxicity scales: Implications for interpreting toxicity data. J Natl Cancer Inst 1993; 85; 38-48

12. Kaplan EL, Meyer P, Nonparametric estimation from incomplete observations. J Am Stat Assoc, 1959; 53; 457- 481

13. Huisman C, Postmus PE, Giaccone $\mathrm{G}$ et all, Second line chemotherapy and its evaluation in small cell lung cancer, Cancer Treat Rev, 1999, 25, 199- 206

14. Von Pavel J, Gatzemeier U, Pujol J1 et al, Phase II comparator study of oral versus intravenous topotecan in patients with chemosensitive small- cell lung cancer, J Clin Oncol 2001; 19: 1743- 1749

Address for correspondence:

Dr. Deyan Davidov,

Department of Chemotherapy, Oncological Center, Medical University, 1 "St. Kliment Ohridsky" Str., 5000 Pleven, Bulgaria

Phone: +359/64/886 317, Fax: +359/64/831634

E-mail: dean_davidov@abv.bg 